\title{
APLIKASI HORMON LHRH-a UNTUK PERKEMBANGAN GONAD DAN PEMIJAHAN INDUK IKAN KERAPU BATIK (Epinephelus microdon)
}

\author{
Tony Setiadharma, Agus Prijono, dan Nyoman Adiasmara Giri
}

\begin{abstract}
ABSTRAK
Percobaan ini dilakukan untuk mengetahui informasi tentang penggunaan hormon LHRH-a terhadap pemijahan dan perkembangan gonad induk kerapu batik (Epinephelus microdon). Induk kerapu batik berukuran 2,15--3,66 kg yang dipelihara dalam 3 tangki volume 30 ton, masingmasing diisi 10 ekor induk terdiri atas 6 ekor jantan dan 4 ekor betina. Pakan yang diberikan berupa ikan rucah dan cumi segar dicampur vit. mix sebanyak $3 \%$ bobot total/hari. Sebagai perlakuan dalam penelitian adalah implantasi hormon LHRH-a dengan dosis $0 \mu \mathrm{g}$ (kontrol), 50 $\mu \mathrm{g}$, dan $100 \mu \mathrm{g} / \mathrm{kg}$. Percobaan dilakukan selama 6 bulan. Hasil percobaan menunjukkan bahwa implantasi hormon berpengaruh terhadap pemijahan dan perkembangan gonad. Pada dosis $100 \mu \mathrm{g} / \mathrm{kg}$ telur berkembang dengan baik, terjadi pemijahan sebanyak 6 kali pada bulan Mei sampai Agustus 2001 dengan jumlah total telur yang dibuahi sebanyak 7.606.000 butir, kemudian pada dosis $50 \mu \mathrm{g} / \mathrm{kg}$ terjadi pemijahan sebanyak 5 kali dengan jumlah total telur yang dibuahi 2.320.000 sedangkan kualitas telur relatif sama. Pada kontrol tidak terjadi pemijahan namun gonadnya berkembang dengan diameter telur bervariasi antara 60--380 $\mu \mathrm{m}$.
\end{abstract}

\section{ABSTRACT: Aplication of LHRH-a hormon implantation on gonadal development and spawning E. microdon marble grouper. By: Tony Setiadharma, Agus Prijono, and Nyoman Adiasmara Giri}

The application study aimed to know the effect of hormones (LHRH-a and HCG) on spawning and gonad development of E. microdon marble grouper. Ten fish of 2.15--3.66 kg body weight comprising of, six females and four males were reared in three $30 \mathrm{~m}^{3}$ concrete tanks and were fed with experimental diet. Three different of $\mathrm{LHRH}$-a hormone used as treatment were: $(A)$ control, $(B)$ $50 \mu \mathrm{g} / \mathrm{kg}$, and (C) $100 \mu \mathrm{g} / \mathrm{kg}$. Result of the experiment showed that hormon implantation of $100 \mu \mathrm{g} /$ $\mathrm{kp}$ doze gave the best result in term of gonadal maturation stage on reproduction, were fish spawned five to six times in May and August giving a total production of 7,606,000 fertilized eggs. Where as that of $50 \mu \mathrm{g} / \mathrm{kg}$ produced five spawnings will a total 2,320,000 fertilized eggs. No spawning accured on control except on gonadal development, where egg diameters variabled between $60--380 \mu \mathrm{m}$.

KEYWORDS: $\quad$ hormone, spawning, gonad, marble grouper, E. microdon

\section{PENDAHULUAN}

Ikan kerapu terutama kerapu hidup merupakan ikan yang mempunyai nilai ekonomis yang sangat mahal di Asia. Beberapa jenis ikan kerapu dari genus Epinephelus sudah dibudidayakan dalam keramba jaring apung (KJA) di Indonesia, Singapura, Thailand, dan Hongkong (Sugama et al., 1986), akan tetapi usaha budi daya tersebut tidak berkembang dengan baik karena terbatasnya sediaan benih. Ikan kerapu batik (Epinephelus microdon) toleran terhadap kekeruhan, salinitas, dan dapat menerima pakan buatan (Purba \& Basyari, 1992), sehingga memungkinkan untuk dibudidayakan di tambak (Khono \& Duary, 1988). Dengan manipulasi lingkungan, pakan, atau dengan rangsangan hormonal, beberapa jenis kerapu telah berhasil dimatangkan gonadnya dan memijah dalam bak terkontrol antara lain ikan kerapu macan, E. fuscoguttatus (Muchari et al., 1991; Mayunar et al., 1991), kerapu bebek, Cromileptes altivelis (Tridjoko et al., 1996; Aslianti et al., 1996), dan kerapu sunu, Plectropoma aerolatus (Slamet \& Rukmana, 1996). Pemijahan induk kerapu dapat dilakukan dalam tangki secara terkontrol dengan merangsang dan memacu menggunakan suntikan hormon (Prijono et al., 1993; Tridjoko et al., 1999) yaitu dengan implantasi pelet hormon $\mathrm{LHRH}$ analog (des-Gly10D-Aa6LHRH-ethylamide) pada dosis 100 $\mu \mathrm{g} / \mathrm{kg}$ bobot tubuh (BW) sangat efektif untuk memacu perkembangan vitelogenin induk ikan. Penggunaan hormon LHRH-a dengan dosis berbeda dalam pematangan gonad dan pemijahan induk kerapu batik diharapkan akan memberikan pengaruh yang nyata sehingga pemijahan induk kerapu dapat berlangsung

\footnotetext{
?) Peneliti pada Balai Besar Riset Perikanan Budidaya Laut, Gondol
} 
secara kontinyu, selanjutnya frekuensi pemijahan dan jumlah telur yang dihasilkan meningkat. Tujuan dari percobaan ini untuk mengetahui informasi tentang penggunaan hormon LHRH-a terhadap pemijahan dan perkembangan gonad induk kerapu batik.

\section{BAHAN DAN METODE}

Hewan uji yang digunakan dalam penelitian adalah induk ikan kerapu batik ( $E$. microdon) ukuran 2,15-$3,66 \mathrm{~kg}$ yang dilakukan selama 6 bulan. Ikan dipelihara dalam 3 buah tangki beton volume $30 \mathrm{~m}^{3}$ dan setiap tangki diisi induk kerapu 10 ekor yang terdiri atas 6 ekor betina dan 4 ekor jantan. Ikan diberi pakan berupa ikan dan cumi segar dicampur dengan vit. mix. Sebagai perlakuan dalam penelitian ini adalah perbedaan dosis hormon LHRH-a yaitu, A. kontrol, B. $50 \mu \mathrm{g}$, dan C. $100 \mu \mathrm{g}$. Pada awal percobaan semua induk secara individu diimplantasi dengan hormon LHRH-a sebanyak 3 kali dengan selang waktu 1 bulan, kecuali pada perlakuan kontrol. Pergantian air dalam pemeliharaan induk sebanyak 300\%--400\% dengan sistem air mengalir. Pengamatan perkembangan go- nad dilakukan setiap bulan (menjelang bulan baru), dengan cara kanulasi yaitu memasukkan selang plastik diameter $0,9 \mathrm{~mm}$ ke dalam lubang kelamin induk betina sedalam $10 \mathrm{~cm}$ dan distriping untuk induk jantan. Berdasarkan diameter telur, dikelompokkan sebagai berikut previtellogenesis (PV) diameter telur $<$ dari $100 \mu \mathrm{m}$, small vitellogenesis (SV) diameter telur 100--250 $\mu \mathrm{m}$, medium vitellogenesis (MV) diameter telur 250--450 um, dan large vitellogenesis (LV) > 450 $\mu \mathrm{m}$. Sperma yang diperoleh dari striping dikelompokkan berdasarkan jumlahnya yaitu positif 1 (sedikit), positif 2 (sedang), dan positif 3 (banyak). Analisis data dilakukan secara deskriptif dan tabulasi.

\section{HASIL DAN BAHASAN}

Sel telur dan sperma induk kerapu batik selama percobaan berlangsung umumnya berkembang baik sejak bulan Juni sampai Agustus. Pada perlakuan dosis $50 \mu \mathrm{g}--100 \mu \mathrm{g}$ terjadi pemijahan sebanyak 5--6 kali dengan frekuensi pemijahan dan kualitas telur yang dihasilkan relatif sama. Pada kontrol tidak terjadi pemijahan (Tabel 1 dan 2).

Tabel 1. Perkembangan gonad induk betina dan sperma induk jantan kerapu batik (Epinephelus microdon) selama percobaan

Table 1. Gonadal developed of male and female grouper broodstock (Epinephelus microdon) during experiment

\begin{tabular}{|c|c|c|c|c|c|c|c|c|c|c|c|}
\hline \multirow{3}{*}{$\begin{array}{c}\text { Dosis } \\
\text { Dosage } \\
(\mu \mathrm{g})\end{array}$} & \multirow{3}{*}{$\begin{array}{l}\text { Bulan } \\
\text { Month }\end{array}$} & \multicolumn{9}{|c|}{ Perkembangan Gonad (Gonad Development) } & \multirow{3}{*}{$\begin{array}{c}\text { Pemijahan } \\
\text { Spawn }\end{array}$} \\
\hline & & \multicolumn{5}{|c|}{ Betina (Female) } & \multicolumn{4}{|c|}{ Jantan (Male) } & \\
\hline & & $\mathrm{Neg}$ & PV & SV & MV & LV & $\mathrm{Neg}$ & +1 & +2 & +3 & \\
\hline Kontrol & April (April) & - & - & - & - & - & - & - & - & - & Tidak memijah \\
\hline \multirow[t]{4}{*}{ Control } & Mei (May) & 2 & 1 & 1 & 2 & - & 1 & 1 & 2 & - & Not spawned \\
\hline & Juni (June) & 2 & - & 2 & 1 & 1 & - & 3 & 1 & - & \\
\hline & Juli (July) & 2 & 1 & 2 & 1 & - & 1 & 3 & - & - & \\
\hline & Agustus (August) & - & - & - & - & - & - & - & - & - & \\
\hline \multirow[t]{5}{*}{50} & April (April) & - & - & - & - & - & - & - & - & - & Memijah 5 kali \\
\hline & Mei (May) & 1 & 1 & 1 & 3 & - & - & 2 & 2 & - & Five times spawned \\
\hline & Juni (June) & 1 & 1 & 1 & 2 & 1 & - & 2 & 2 & - & \\
\hline & Juli (July) & 1 & 2 & 1 & 1 & 1 & 1 & - & 3 & - & \\
\hline & Agustus (August) & - & - & - & - & - & - & - & - & - & \\
\hline \multirow[t]{5}{*}{100} & April (April) & - & - & - & - & - & - & - & - & - & Mermijah 6 kali \\
\hline & Mei (May) & 4 & 1 & 1 & 1 & - & 1 & - & 2 & - & Six times spawned \\
\hline & Juni (June) & 2 & - & - & 2 & 2 & 1 & 1 & 3 & - & \\
\hline & Juli (July) & 1 & - & 1 & 2 & 2 & 1 & 1 & 2 & - & \\
\hline & Agustus (August) & - & - & - & - & - & - & - & - & - & \\
\hline
\end{tabular}

Neg :Negative (Kosong)

PV :Previtellogenic (Diameter telur $<100 \mu \mathrm{m}$ )

SV :Smallvitellogenic (Diameter telur 100--250 $\mu \mathrm{m}$ )

MV :Mediumvitellogenic (Diameter telur 250--450 $\mu \mathrm{m}$ )

LV :Largevitellogenic (Diameter $>450 \mu \mathrm{m}$ )

Positive 1--3 = Amount of sperm (Kualitas sperma tingkat 1--3) 
Tabel 2. Pengamatan pemijahan induk kerapu batik (Epinephelus microdon) selama percobaan Table 2. Observed of grouper (Epinephelus microdon) during experiment

\begin{tabular}{|c|c|c|c|c|c|c|}
\hline $\begin{array}{c}\text { Dosis } \\
\text { Dosage } \\
(\mu \mathrm{g})\end{array}$ & $\begin{array}{l}\text { Bulan } \\
\text { Month }\end{array}$ & $\begin{array}{l}\text { Jumlah telur } \\
\text { Total eggs }\end{array}$ & $\begin{array}{c}\text { Telur } \\
\text { mengapung } \\
\text { Floating eggs }\end{array}$ & $\begin{array}{c}\text { Telur } \\
\text { mengendap } \\
\text { Singking eggs }\end{array}$ & $\begin{array}{c}\text { Daya tetas } \\
\text { Hatching } \\
\text { rate }(\%)\end{array}$ & $\begin{array}{c}\text { Keterangan } \\
\text { Remark }\end{array}$ \\
\hline Kontrol & Juni (June) & - & - & - & - & Tidak memijah \\
\hline \multirow[t]{2}{*}{ Control } & Juli (July) & - & - & - & - & Not spawned \\
\hline & Agustus (August) & - & - & - & - & \\
\hline \multirow[t]{3}{*}{50} & Juni (June) & 950,000 & 850,000 & 100,000 & 55 & Memijah 2 kali \\
\hline & Juli (July) & 500,000 & 360,000 & 140,000 & 70 & Memijah 1 kali \\
\hline & Agustus (August) & 870,000 & 680,000 & 190,000 & 80 & Memijah 2 kali \\
\hline \multirow{4}{*}{100} & Juni (lune) & & & & & Mamiah $1 \mathrm{k}$ \\
\hline & Juli (July) & $6,710,000$ & $\begin{array}{r}710,000 \\
6,350,000\end{array}$ & $\begin{array}{r}40,000 \\
360,000\end{array}$ & $\begin{array}{l}60 \\
80\end{array}$ & $\begin{array}{l}\text { Memijah } 1 \text { kali } \\
\text { Memijah } 4 \text { kali }\end{array}$ \\
\hline & Agustus (August) & 146,000 & 90,000 & 56,000 & 75 & Memijah 1 kali \\
\hline & & & & & & One-four time spawned \\
\hline
\end{tabular}

Gonad dan sperma induk kerapu batik pada umumnya berkembang hingga medium dan large vitelogenik (MV dan LV) dengan diameter 250--450 $\mu \mathrm{m}$ dan $>450 \mu \mathrm{m}$ terjadi pada bulan Juni sampai Agustus (Tabel 1 dan 2). Pada penggunaan dosis hormon $50 \mu \mathrm{g}$ dan $100 \mu \mathrm{g}$ yang diimplantasi pada induk kerapu batik telah terjadi peningkatan perkembangan gonad pada tiap bulan dan pemijahan sebanyak 5--6 kali dengan jumlah total telur yang dibuahi antara 2.320.000--7.606.000 butir, sedangkan pada kontrol (tanpa implantasi hormon) gonad berkembang tetapi tidak memijah. Dengan demikian telah terjadi rangsangan pada proses perkembangan gonad induk kerapu sebagai hasil implantasi hormon. Penggunaan implantasi hormon dalam reproduksi buatan telah berhasil dengan baik seperti halnya pada ikan bandeng (Lee et al., 1986; Prijono et al., 1993) dan ikan Nassau grouper, Epinephelus striatus (Watanabe, 1995). Dari hasil pengamatan terlihat bahwa telah terjadi penambahan bobot yang sejalan dengan peningkatan diameter telur saat induk mau memijah. Menurut Effendi (1979) dan Mayunar (1992), dalam proses reproduksi sebagian besar hasil metabolisme digunakan untuk perkembangan gonad. Pada penggunaan hormon dengan dosis 50--100 $\mu$ g terlihat lebih baik tingkat perkembangan gonadnya daripada tanpa hormon (kontrol) karena proses vitellogenesis yang ada lebih aktif, selanjutnya organ pituitari berfungsi secara aktif dan secara timbal balik membantu gonadotropin pada tahapan pemijahan (Tamaru et al., 1988).

\section{KESIMPULAN}

Hasil percobaan menunjukkan bahwa implantasi hormon LHRH-a dosis 50-100 $\mu \mathrm{g} / \mathrm{kg}$ pada induk kerapu batik berpengaruh terhadap perkembangan gonad dan pemijahan. Implantasi hormon dosis $50 \mu \mathrm{g} / \mathrm{kg}$ memperlihatkan pemijahan sebanyak 5 kali dengan jumlah total telur 2.320.000, sedang pada dosis 100 $\mu \mathrm{g} / \mathrm{kg}$ sebanyak 6 kali dengan jumlah telur 7.606 .000 butir sedangkan pada kontrol belum terjadi pemijahan.

\section{DAFTAR PUSTAKA}

Aslianti, T. 1996. Pemeliharaan larva kerapu bebek, Cromileptes altivelis dengan padat tebar berbeda. J. Pen. Per. Indonesia, 1(2): 6--12.

Crim, L.W. 1985. Methods for acute and cronic hormone administration in fish, In Proceeding for a Workshop held at Tungkang Marine Laboratory Taiwan, April 22--24, p: 1--9.

Effendi, M.I. 1979. Metodologi Biologi Perikanan. Cetakan pertama. Yayasan Dewi Sri, Bogor: 112 pp.

Kohno, H. and M. Dauray. 1988. Effect of continous lighting of growth and survive of fish feeding larvae. Rabbithfish, Siganus guttatus. Aquaculture 27:113-136.

Lee, C.S., C.S. Tamaru, and C.D. Kelly. 1986. Technique making chronic release LHRH-a and 17 alphamethyltestosteron pellet for intramusculer implantation in fishes. Aquaculture. 59: 161--168.

Mayunar, P.T. Imanto, S. Diani, dan T. Yokonawa.1991. Pemijahan ikan kerapu macan, Epinephelus fuscoguttatus. Bull. Pen. Per. (Terbitan khusus) 2: 15$-22$.

Mucharie, A. Supriatna, R. Purba, T. Ahmad, dan Kohno. 1991. Pemeliharaan larva kerapu macan, Epinephelus fuscoguttatus. Bull. Pen. Per. (Terbitan khusus) 2: 43--52.

Purba, R. dan A. Basyari. 1992. Pengaruh padat penebaran terhadap kelangsungan hidup dan biomass ikan kerapu lumpur (E. suillus) di tambak. J. Pen. Budidaya Pantai, 8 (5): 51--55.

Prijono A., T. Ahmad, dan T. Setiadharma. 1993. Pengaruh penambahan nutrisi pakan terhadap 
perkembangan gonad ikan bandeng. J. Pen. Budidaya Pantai, 9 (1): 51--57.

Sugama K., Waspada, and H. Tanaka. 1986. Growth comparison some species of groupers culture in floating net cages, Sci, Rep. Mar. Res JICA, ATA-192, p. $211--214$.

Slamet B. dan T. Rukmana. 1996. Pengamatan pada pemijahan induk dan perkembangan awal larva ikan kerapu sunu (Plectropoma areolatus), Seminar Nasional Biologi XI, Depok, 11 pp.

Tamaru, C.S., C.S. Lee, C.D. Kelly, J.E. Banno, P.Y. Ha, K. Aida, and I. Hanyu. 1988. Characterizing the stage of maturity most receptive to an acute LHRH-a therapy for inducing milkfish (Chanos chanos) to spawn. Aquaculture. 74: 147--163.
Tridjoko, B. Slamet, dan D. Makatutu. 1999. Pengamatan pemijahan dan perkembangan telur ikan kerapu bebek (Cromileptes altivelis) pada bak secara terkontrol. J. Pen. Perikanan Indonesia 2 (2): 55--62.

Tridjoko, B. Slamet, dan D. Makatutu. 1999. Pemantangan induk kerapu bebek (Cromileptes altivelis) dengan rangsangan suntikan hormon LHRH-a, 17 methyltestosteron. J. Pen. Perik. Indonesia, III(4):30-34.

Watanabe, W.O. Simon, C.E. Elleen, P.E. William, O.H. Christopher, D.K. Aaron, M. Cheng S.L., and Paul, K.B. 1995. Progress in Controlled Breeding of Nassau Grouper, Epinephelus striatus Broodstock by Hormon Induction. Aquaculture, 138:205--219. 